\title{
Mucosal Tears Can Occur Spontaneously in Collagenous Colitis
}

\section{A. Koulaouzidis' ${ }^{1}$ J. A. Henry ${ }^{2}$,}

\section{A. A. Saeed ${ }^{1}$}

${ }^{1}$ Combined Medical Gastroenterology

Unit, Queen Elizabeth Hospital,

Gateshead, UK

${ }^{2}$ Histocytopathology Department, Queen Elizabeth Hospital, Gateshead, UK
Corresponding Author

\section{A. Saeed, M.D.}

1 Sheriff Mount South, Old Durham Road Gateshead NE9 6SX, Tyne and Wear, UK Fax: $\quad+441913653$

E-mail: asaeed@doctors.org.uk
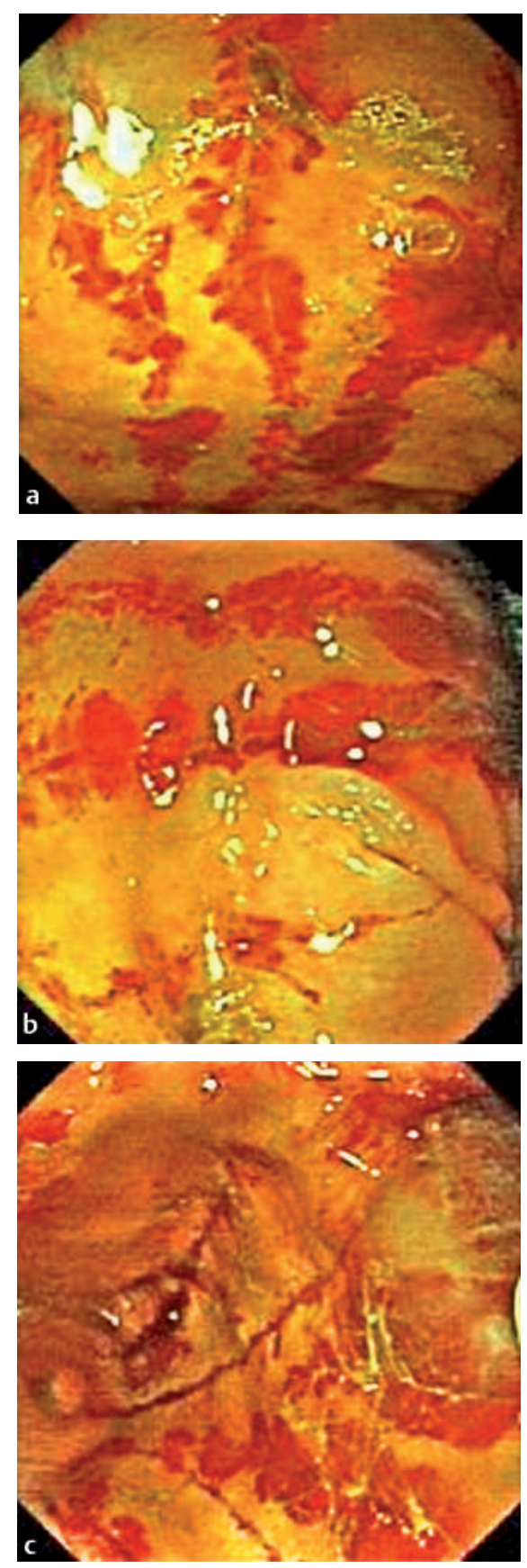

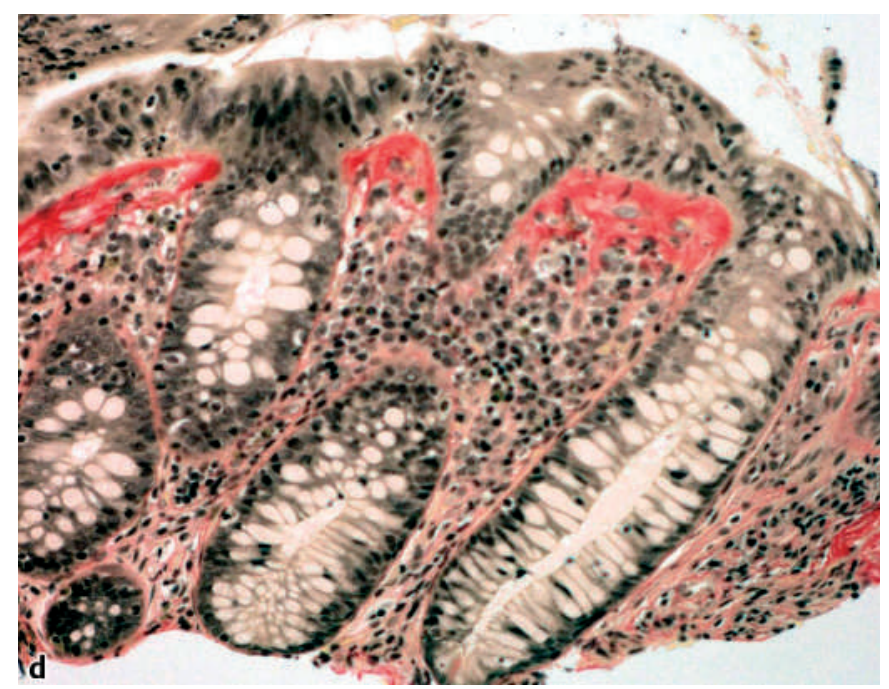

Figure 1 An 83-year-old lady with intractable non-bloody diarrhoea of over 3 months' duration, was found to be anaemic, with a haemoglobin value of $10.0 \mathrm{~g} / \mathrm{dl}$ (normal range $11.5-16.5 \mathrm{~g} / \mathrm{dl}$ ) and mean corpuscular volume of $72.6 \mathrm{fl}$ (normal 80-102 fl). Oesophagogastroduodenoscopy and duodenal biopsies were normal. At colonoscopy, the caecum was easily reached after gentle insufflation, and discrete linear mucosal breaks were found. We propose that these mucosal tears were spontaneous, not caused by scope trauma but by the stiffness of the colonic wall and normal contractions of the bowel. Mucosal tears in the caecum in collagenous colitis have not been described before. In addition, these tears probably caused this patient's iron-deficiency anaemia. a-c Mucosal tears. d Van Gieson stain; original magnification $\times 100$. 